\title{
To study the Knowledge regarding immunization schedule among parents and the source of information regarding vaccination
}

\author{
Agrawal A ${ }^{1}$, Hanspal $\mathbf{R}^{2}$ \\ ${ }^{1}$ Dr Astha Agrawal, Associate Professor, Department of Pediatrics, Shridev Suman, Subharti Medical College, Dehradun, \\ India, ${ }^{2}$ Dr Roopa Hanspal, Associate Professor, Department of Community Medicine, Shridev Suman, Subharti Medical \\ College, Dehradun, India.
}

Address for Correspondence: Dr Astha Agrawal, Email: drasthaagrawal@gmail.com

\begin{abstract}
Background: Immunization, the most cost-effective public health intervention, continues to be under-used. It is profoundly tragic that almost two million children still die each year from disease for which vaccines are available at low cost. The aim of study is to correlate parents knowledge practices and children immunization completeness. Material \& Methods: A one year prospective cross-sectional study was carried out on children admitted in Pediatric ward of Kamla Nehru hospital, Gandhi Medical College, Bhopal. Total 240 cases as any of the six VPDS were studied according to a pre-designed proforma. Knowledge about vaccination, age, place and person were collected among parents and recorded along with the reason for non-vaccination. A comparison with trend five years back in the same hospital was done. Result: In present study the highest incidence was of TB $47.92 \%$ followed by tetanus, measles, diphtheria $\&$ neotetanus. Highest mortality is of tetanus neonatorum followed by tetanus, Diphtheria, Measles \& tuberculosis in descending order, among 240 admitted patients. The incidence of VPDS was higher among unvaccinated child as compared to vaccinated child except tuberculosis where vaccination rate was higher $(52.17 \%)$ and all VPDS were much common in illiterate fathers and mothers. Conclusion: There is a need to increase awareness and knowledge about the benefits and importance of vaccination, as well as the harmful consequences of non-complete immunization. A planned educational programme is needed; the educational level of the parents needs to be taken into consideration when the programme is planned, especially as regards those with a lower educational level.
\end{abstract}

Keywords: Immunization, VPDS, Knowledge

\section{Introduction}

The six vaccine preventable diseases kill, blind, cripple and cause mental damage to about ten million children worldwide each year, Immunization of children against serious communicable diseases is the most cost effective strategy to decrease overall morbidity and mortality among children [1]. In order to accomplish this strategy, high coverage of vaccination is essential to be maintained [2]. Immunization is one of the cost effective interventions to prevent a series of major illness. It prevents 2 million deaths per year worldwide and is widely considered to be" overwhelmingly good" by the scientific community. Vaccination coverage has now reached a plateau in many developing countries and even where good coverage has been achieved; reaching the children who were yet to be vaccinated has

Manuscript received: $5^{\text {th }}$ November 2016

Reviewed: $16^{\text {th }}$ November 2016

Author Corrected; $28^{\text {th }}$ November 2016

Accepted for Publication: $14^{\text {th }}$ December 2016 proved difficult [3]. Factors such as knowledge, attitude and practices of parents contribute to contribute to success or failure of immunizations program. Information about knowledge, attitude and practices about immunization is lacking in developing countries [4].

VPDs contribute significantly to Under five mortality. In India Under five mortality is $68.8 / 1000$ [5]. Routine immunization is one of the most cost effective public health interventions \& was 1st introduced in India in 1978. Yet despite the concrete efforts of government \& other health agencies, a large proportion of vulnerable infants \& children in India remain unimmunized. India has the highest no. (approx. 10 million) of such children in the world [6]. National Family Health Survey (20052006) reports that only $43.5 \%$ of children in India received all of their primary vaccines by 12 months of 
age1. Main reasons identified for poor coverage includes inadequacy of community participation in Routine Immunization \& IEC activities [7]. Therefore the study was carried out to assess the level of knowledge and attitude of mothers of Under Five children regarding VPDs \& routine immunization \& at the same time mothers can be motivated by updating their level of knowledge regarding the importance of immunization, as the mothers of Under Five children are very receptive to advice given by doctors \& paramedical staff regarding the health of the child $[7,8]$.

\section{Material and Methods}

Total 240 cases as any of the six VPDS were studied according to a pre-designed proforma. Knowledge about vaccination, age, place and person was collected among parents and recorded along with the reason for non-vaccination. A comparison with trend five years back in the same hospital was done.

Study design- A prospective cohort observational study.

Settings- Kamla Nehru hospital, Gandhi Medical College, Bhopal, MP.

Inclusion criteria- Age less than 6 years, six vaccine preventable diseases - tuberculosis, diphtheria, pertusis, tetanus, polio, measles admitted in pediatric ward were selected.

Exclusion criteria- Age more than 6years, outside admission, other vaccine preventable diseases.

Technique: The relevant information were collected from parents of the children by questionnaire method on a predesigned proforma.

Data collection: Detailed information regarding age, sex, religion, locality, month of admission, immunization status of the patient, source of vaccination, history of contact with tuberculosis and measles, clinical presentation and knowledge and practices of parents regarding immunization were recorded. Finally, the result that whether the patient was relieved or absconded or left against medical advice (LAMA) or expired was recorded. Regarding Tetanus neonatorum, the information about the immunization of mother with two doses of tetanus toxoid, place of delivery, cord care practices, clinical presentations, etc. were recorded. These data were finally depicted in the tabular form observation section.

Statistical Analysis- odds ratio and $\log$ odd ratio with chisquare test of significance were used for statistical analysis of data. Statistical test of significance was defined as $\mathrm{p}<0.05$.

\section{Results}

Total 240 cases as any of the six VPDS were studied according to a pre-designed proforma. Knowledge about vaccination, age, place and person were collected among parents and recorded along with the reason for non-vaccination. A comparison with trend five years back in the same hospital was done.

Table-1: Total admission and deaths in VPD during study period.

\begin{tabular}{|c|c|c|c|c|c|c|}
\hline Disease & \multicolumn{2}{|c|}{ Total Admission } & \multicolumn{2}{c|}{ Total Deaths } & \multicolumn{2}{c|}{ \% Mortality } \\
\hline & Present & Previous & Present & Previous & Present & Previous \\
\hline TB & 115 & 153 & 5 & 15 & 4.3 & 9.8 \\
\hline Measles & 29 & 55 & 2 & 06 & 6.9 & 10.9 \\
\hline Diphtheria & 29 & 2 & 12 & 09 & 41.38 & 40.9 \\
\hline Tetanus & 43 & 45 & 18 & 09 & 41.86 & 20 \\
\hline $\begin{array}{c}\text { Neonatal } \\
\text { tetanus }\end{array}$ & 24 & 14 & 12 & 07 & 50 & 50 \\
\hline Total & $\mathbf{2 4 0}$ & $\mathbf{2 8 9}$ & $\mathbf{7 9}$ & $\mathbf{3 6}$ & $\mathbf{2 0 . 4}$ & $\mathbf{1 2 . 4 5}$ \\
\hline
\end{tabular}

Above table show that in present study the highest mortality is of tetanus neonatorum followed by tetanus, Diphtheria, Measles \& tuberculosis in descending order and it also shows that in previous study the highest mortality are of Tetanus Neonatorum followed by Diphtheria, Tetanus, Measles and tuberculosis in descending order. 
Table-2: Incidence rate of VPDS during study period.

\begin{tabular}{|c|c|c|c|c|}
\hline \multirow{2}{*}{ Disease } & \multicolumn{2}{|c|}{ Total cases } & \multicolumn{2}{c|}{ Incidence (\%) } \\
\cline { 2 - 5 } & Present & Previous & 47.92 & 12.08 \\
\hline TB & 115 & 55 & 12.08 & 19.00 \\
\hline Measles & 29 & 22 & 17.92 & 15.50 \\
\hline Diphtheria & 29 & 45 & 10 & 4.84 \\
\hline
\end{tabular}

Above table shows in present study that out of all VPD's highest incidence was of TB $47.92 \%$ followed by tetanus, measles, diphtheria \& neotetanus. Total Admission VPDS $=240$.

And In previous study, out of all VPDS highest incidence was of TB followed by Measles, tetanus, Diphtheria and Tetanus Neonatorum. Total Admission VPD $=289$

Table-3: Immunization status wise distribution of VPDS during study period.

\begin{tabular}{|c|c|c|c|c|c|}
\hline Disease & Total & Vaccinated & \% & Unvaccinated & \% \\
\hline TB & 115 & 60 & 52.17 & 55 & 47.83 \\
\hline Measles & 28 & 2 & 6.9 & 27 & 93.1 \\
\hline Diphtheria & 29 & 5 & 17.24 & 12 & 41.38 \\
\hline Tetanus & 43 & 5 & 11.63 & 38 & 88.37 \\
\hline
\end{tabular}

Above mentioned table shows that the incidence of VPDS was higher among unvaccinated child as compared to vaccinated child except tuberculosis where vaccination rate was higher $(52.17 \%)$

Table-4: Distribution of cases in relation to maternal education.

\begin{tabular}{|c|c|c|c|c|c|}
\hline Disease & Illiterate & Primary & High school & College & Total \\
\hline TB & 94 & 19 & 2 & 0 & 115 \\
\hline Measles & 24 & 5 & 0 & 0 & 29 \\
\hline Tetanus & 38 & 5 & 0 & 0 & 43 \\
\hline Diphtheria & 17 & 12 & 0 & 0 & 29 \\
\hline
\end{tabular}

The above table shows that all VPDS were much more common in illiterate mothers.

Table-5: Distribution of cases in relation to paternal education.

\begin{tabular}{|c|c|c|c|c|c|}
\hline Disease & Illiterate & Primary & High school & College & Total \\
\hline TB & 74 & 22 & 14 & 5 & 115 \\
\hline Measles & 20 & 7 & 2 & 0 & 29 \\
\hline Tetanus & 36 & 5 & 2 & 0 & 29 \\
\hline Diphtheria & 17 & 10 & 5 & 0 & 29 \\
\hline
\end{tabular}

The above table shows that all VPDS were much common in illiterate fathers. 
Table-6: Source of information regarding vaccination.

\begin{tabular}{|c|c|}
\hline Informer & Percentage \\
\hline Health worker & $88 \%$ \\
\hline Self & $22 \%$ \\
\hline Medical practitioner & $32 \%$ \\
\hline Relatives & $12 \%$ \\
\hline Neighbours & $28 \%$ \\
\hline Media & $26 \%$ \\
\hline
\end{tabular}

Above table shows that highest source of information regarding vaccination are health workers followed by medical practitioners, neighbours, media then self and relatives.

Table-7: Reason for non- vaccination.

\begin{tabular}{|c|c|}
\hline Reason for non- vaccination & Percentage \\
\hline Lack of knowledge about vaccination, time and place of vaccination & $92 \%$ \\
\hline Wrong idea when to vaccinate the child & $21 \%$ \\
\hline No faith in vaccination & $18 \%$ \\
\hline Time not available & $64 \%$ \\
\hline Place of vaccination & $78 \%$ \\
\hline Vaccinator not present & $26 \%$ \\
\hline Child illness & $38 \%$ \\
\hline No male member to take for vaccination & $42 \%$ \\
\hline Apathy & \\
\hline
\end{tabular}

Above table shows that highest reason for non vaccination is Lack of knowledge about vaccination, time and place of vaccination, followed by wrong idea, no faith in vaccination and availability of time.

\section{Discussion}

It is widely accepted that childhood immunization programs have played a great part in the prevention of many diseases; hence, vaccination coverage is an indirect way to assess child health care from the point of view of public health [9]. Eighty percent of the parents were unaware that not all the vaccines are administered under the national program and there are few vaccines which are in the recommended immunization schedule and need to be taken in addition to the routine vaccines. Similar results were seen by Inamder et al in Madhya Pradesh and Angelillo et al in Italy $[10,11]$.
Among those who have heard about the vaccine, more than half were not aware of the diseases against which the vaccine confers protection. These results are similar to the studies by Mony PK et al and Mapatano MA et al where awareness regarding vaccine availability was moderate, but the knowledge regarding dosage schedule and diseases prevented was low [12,13]. Though 40\% parents have heard about cervical cancer vaccine, only $15 \%$ of them had knowledge regarding the vaccine and knew about the human papilloma virus. Similar results have been shown by Tang CW et al in Taiwan where only $13 \%$ had heard of the HPV vaccine [14]. 
There were many misconceptions regarding vaccine efficacy and duration of protection. Respondents were noted to be not well aware of the possible side effects of vaccines, with the exception of fever (46\%), redness $(22 \%)$ and pain $(23 \%)$. Seizures though uncommon is an important side effect which only a meagre percent of the parents $(1 \%)$ are aware of. Similar results were obtained by the EKOS research associates, Inamder et al and Tang CW et al $[14,15]$.

$92 \%$ of our patients have Lack of knowledge about vaccination, . In the study by EKOS research associates, most parents are confident in the safety of childhood vaccines, with $65 \%$ of parents rating them as highly safe, $30 \%$ rating them as moderately safe and very few saying that they are unsafe [16].

In the present study health workers are common source of information followed by medical practitioners, and neighbours. In contrast physicians are a main source of information regarding immunization accounting to $55 \%$. Internet (14\%), pamphlets at hospital (11\%) and friends $(13 \%)$ were the next main source of information in a study [15]. Ekos research associate showed that parents rely mostly on Internet (63\%) and physicians (54\%). Coniglio MA et al, Angelillo et al and Inamder et al also showed that most parents sought information about vaccines from the physicians [17].

Thirty six percent of the parents have wrong idea when to vaccinate the child. In a study conducted by Center for health services research and development, Armenia, most of the parents indicated that they trusted the vaccines provided at public facilities more than the vaccines in private facilities [18].

In our study all VPDS were much more common in illiterate mothers and fathers same as study done byJamman et al [19] they were found that the knowledge score was lower in those women with a compromised educational standard. It is a truism that knowledge increases with education. It is however, questionable whether those more informed women actually received their information from health professionals [19].

In a study done by Jose et al [20] there was a significant association between knowledge and exposure to mass media in relation to immunization among mothers of under five children as the calculated value is more than the table value at 0.05 level of significance. A cross sectional study was conducted to assess the awareness
\& knowledge of mothers of Under Five children regarding Immunization. The main sources of information on immunization was obtained from Anganwadi Worker (47\%) \& Television (35\%) [20].

\section{Conclusion}

The present study highlighted the knowledge of mothers on immunization. A better understanding of health issues associated with the immunization constituted a challenge for clinician and researchers. So there is a great lot scope for exploring this area. Research should be conducted to identify the attitude and practice of mothers on immunization. Low literacy level of mothers is a matter of worry. Some of them don't know about the diseases for which their child is being immunized, So there is a dire need to arrange for health education program sessions for mothers of Under five children with main emphasis on importance of vaccination \& Vaccine Preventable Diseases (VPDs).

\section{Funding: Nil, Conflict of interest: Nil Permission from IRB: Yes}

\section{Bibliography}

1. Nicoll A, Elliman D, Begg NT. Immunization: causes of failure and strategies and tactics for success. BMJ 1989; 299(30): 808-12.

2. Farag MK, Al-Mazrou YY, Al-Jefry M, Al-Shehri SN, Baldo $\mathrm{MH}$, Farghali M. National immunization coverage Saudi Arabia. Journal of Tropical Pediatrics 1995; 41:59-67.1.Med Pregl. 2005 Jul-Aug;58 (7-8): $333-41$.

3. Petrovic V, Seguljev Z, Gajin B. Maintaining the cold chain for vaccines. Med Preg1.2005; 58:333-41.

4. Immunization Handbook for Medical officers; Dept of Health \& Family Welfare, Govt. Of India;page10,15 available on nihfw.org

5. World Bank, World Development Indicators (www.google.com/publicdata as accessed on 13.5.2010) https://www.google.com/publicdata

6. Singh MC, Badole CM, Singh MP. Immunization coverage\& knowledge \& practice of mothers regarding Immunization in Rural India. Indian J. Pub.Hlth. 1994; 38. 103-7.

7. D Adeyinka, O Oladimeji, F Adeyinka, C Aimakhu Uptake Of Childhood Immunization Among Mothers 
Of Under-Five In Southwestern Nigeria The Internet Journal of Epidemiology. 2008 Volume 7 Number 2. available on http://ispub.com/IJE/7/2/3255\#

8. Rahul Sharma \& Sanjiv K Bhasin. Routine Immunization - Do People Know About It? A Study Among Caretakers of Children Attending Pulse Polio Immunization in East Delhi. Indian Journal of Community Medicine. 2008 January, 33(1); 31-9.

9. Inamdar $\mathrm{M}$, Piparsania $\mathrm{S}$, Inamdar $\mathrm{S}$, Singh $\mathrm{K}$. Exploring the causes of low immunisation status in school going children. Online J Health Allied Sci. 2011;10(4):3.www.ojhas.org/issue40/2011-4-3.htm

10. Angelillo IF, Ricciardi G, Rossi P, Pantisano P, Langiano E, Pavia M. Mothers and vaccination: knowledge, attitudes and behavior in Italy. Bull World Health Organ. 1999;77(3):224-9.

11. Mony P, Bose A, Dutta AK, Rose JS, Harikrishan B, Alvi A et al. Awareness, utilization and cost of newer childhood vaccines in a lower middle and middle class urban population of Vellore town, South India. Indian Pediatr. 1999;36:954-5.www.ijpediatrics.com

12. Mapatano MA, Kayembe K, Piripiri L, Nyandwe K. Immunisation-related knowledge, attitudes and practices of mothers in Kinshasa, democratic republic of the Congo. SA FamPract. 2008; 50:61-6. www.ajol.info

13. Tang CW, Huang SH, Weng KP, Ger LP, Hsieh KS. Parents' views about the vaccination program in
Taiwan. Pediatr Neonatol. 2011 Apr;52(2):98-102. doi: 10.1016/j.pedneo.2011.02.009. Epub 2011 Mar 21.

14. What do parents think? Knowledge and awareness about newer vaccines: a cross-sectional study in South Indian cityhttps: //www.ncbi.nlm.nih. gov/pmcInt J Contemp Pediatr. 2016; 3(4): 1301-1306.

15. Bakhache P, Rodrigo C, Davie S, Ahuja A, Sudovar B, Crudup T et al. Health care providers' and parents' attitudes toward administration of new infant vaccines a multinational survey. Eur J Pediatr. 2013;172(4):48592link.springer.com/article

16. Coniglio MA, Platania M, Privitera D, Giammanco G, Pignato S. Parents' attitudes and behaviours towards recommended vaccinations in Sicily, Italy. BMC Public Health. 2011;11:305.

17. UNICEF. Formative research on perceptions, attitudes and practices towards immunisation and introduction of new vaccines in Armenia: a qualitative study. Armenia; 2012. http://auachsr.com/

18. Jamman Al-Zahrani knowledge, attitude and practice of parents towards childhood vaccination majmaah j. Health sciences, 2013 - Vol. 1, No. 1. https: // www.mu.edu.sa

19. Kapoor and vyas et al. Awareness and knowledge of mothers of under five children regarding immunization in Ahmedabad. h e a $1 \mathrm{t} \mathrm{h} 1 \mathrm{i} \mathrm{n}$ e ISSN 2229-337X Volume 1 Issue 1 July-December 2010 Pages| 12-15 www.iapsmgc.org/index.

\section{How to cite this article?}

Agrawal A, Hanspal R. To study the Knowledge regarding immunization schedule among parents and the source of information regarding vaccination. J PediatrRes.2016;3(12):869-874.doi:10.17511/ijpr.2016.i12.02. 